\title{
Vasculoprotective Effects of Apolipoprotein Mimetic Peptides: An Evolv- ing Paradigm in HDL Therapy
}

\author{
C. Roger White ${ }^{1, *}$, Geeta Datta ${ }^{2}$, Paulina Mochon ${ }^{1}$, Zhenghao Zhang ${ }^{1}$, Ollie Kelly ${ }^{1}$, \\ Christine Curcio ${ }^{3}$, Dale Parks ${ }^{4}$, Mayakonda Palgunachari ${ }^{2}$, Shaila Handattu ${ }^{2}$, Himanshu Gupta ${ }^{1}$, \\ David W. Garber ${ }^{2}$ and G.M. Anantharamaiah ${ }^{2,5}$
}

\author{
${ }^{I}$ From the Department of Medicine, Division of Cardiovascular Disease and ${ }^{2}$ the Division of Gerontology, Geriatric \\ Medicine and Palliative Care and the ${ }^{3}$ Departments of Ophthalmology, ${ }^{4}$ Anesthesiology and Biochemistry and ${ }^{5}$ Molecu- \\ lar Genetics, University of Alabama at Birmingham, Birmingham, AL, USA
}

\begin{abstract}
Anti-atherogenic effects of high density lipoprotein (HDL) and its major protein component apolipoprotein A-I (apoA-I) are principally thought to be due to their ability to mediate reverse cholesterol transport. These agents also possess anti-oxidant properties that prevent the oxidative modification of low density lipoprotein (LDL) and antiinflammatory properties that include inhibition of endothelial cell adhesion molecule expression. Results of the Framingham study revealed that a reduction in HDL levels is an independent risk factor for coronary artery disease (CAD). Accordingly, there has been considerable interest in developing new therapies that specifically elevate HDL cholesterol. However, recent evidence suggests that increasing circulating HDL cholesterol levels alone is not sufficient as a mode of HDL therapy. Rather, therapeutic approaches that increase the functional properties of HDL may be superior to simply raising the levels of HDL per se. Our laboratory has pioneered the development of synthetic, apolipoprotein mimetic peptides which are structurally and functionally similar to apoA-I but possess unique structural homology to the lipid-associating domains of apoA-I. The apoA-I mimetic peptide 4F inhibits atherogenic lesion formation in murine models of atherosclerosis. This effect is related to the ability of $4 \mathrm{~F}$ to induce the formation of pre- $\beta$ HDL particles that are enriched in apoA-I and paraoxonase. $4 \mathrm{~F}$ also possesses anti-inflammatory and anti-oxidant properties that are independent of its effect on HDL quality per se. Recent studies suggest that $4 \mathrm{~F}$ stimulates the expression of the antioxidant enzymes heme oxygenase and superoxide dismutase and inhibits superoxide anion formation in blood vessels of diabetic, hypercholesterolemic and sickle cell disease mice. The goal of this review is to discuss HDL-dependent and -independent mechanisms by which apoA-I mimetic peptides reduce vascular injury in experimental animal models.
\end{abstract}

Keywords: ApoA-I, HDL, mimetic peptides, CAD risk, atherosclerosis, endothelial function.

\section{INTRODUCTION}

Since its inception over 50 years ago, the Framingham Heart Study has provided extensive insight into mechanisms underlying the development and progression of coronary artery disease (CAD) as well as associated risk factors. Early trial results clearly demonstrated a relationship between elevated serum cholesterol and CAD risk and cardiovascular (CV) death [1]. This relationship has been validated by clinical studies showing that HMG-CoA reductase inhibitors (statins) reduce CAD risk by approximately $25-30 \%[2,3]$. The Framingham Study also provided insight into the relationship between HDL cholesterol levels and CAD risk [1]. Study participants with a "normal" LDL (100 mg/dl) and a high HDL (65-85 mg/dl) were found to be at low risk for a CV event [4]. In subjects with normal LDL, but reduced HDL, CAD risk significantly increased. Low serum HDL

Address correspondence to this author at the Vascular Biology and Hypertension Program, 1046 Zeigler Research Building, 703 South 19th St., Birmingham, AL 35294-0007, USA; Tel: 205 934-1296; Fax: 205 934-0424; E-mail: crwhite@uab.edu

GMA is a Principal in Bruin Pharma, Inc. was thus identified as an independent risk factor for CAD [4]. This observation has fueled interest in the development of new therapies that specifically elevate HDL cholesterol [5].

Several commonly prescribed medications influence serum HDL levels by stimulating hepatic apolipoprotein (apo) A-I expression. Fibrates are agonists for peroxisome proliferator activated receptor- $\alpha$. Lipid lowering effects of fibrates are due to their ability to stimulate expression of not only apoA-I, but also apoA-II and lipoprotein lipase, a mediator of cellular triglyceride uptake [6-8]. Niacin is an effective agent for raising HDL, resulting in a $20-35 \%$ increase in circulating levels of this lipoprotein particle [9]. Statins are used extensively in hyperlipidemic patients to lower LDL cholesterol. This class of drug is reported to increase HDL levels by $3-12 \%[10,11]$. Similar to fibrates and niacin, statins exert a stimulatory effect on apoA-I synthesis, leading to an increase in HDL particle number [12]. Whether this modest increase in HDL in patients taking statins translates into a reduction in CAD risk is unclear. Analyses of 3 major randomized trials showed that a reduction in CAD event rates in 
patients taking pravastatin could not be ascribed to an increase in circulating HDL concentration per se [11].

Recent efforts in the field of HDL therapeutics have focused on the development of cholesteryl ester transfer protein (CETP) inhibitors. CETP mediates the transfer of cholesteryl esters from HDL to VLDL, thereby reducing HDL levels. CETP inhibitors are thought to reduce atherogenicity by increasing the levels of HDL. Laboratory studies showed that introduction of the human CETP gene in mice, a species that is deficient in CETP protein, reduces HDL levels and stimulates the formation of fatty lesions in the arterial wall [13]. Conversely, diet-induced atherosclerosis in rabbits, a species that expresses high levels of CETP, could be reduced by the CETP inhibitor torcetrapib [14]. Studies in human subjects with low HDL showed that torcetrapib induced a prominent increase in serum HDL (61\% increase) [15]. The ILLUMINATE trial was subsequently designed to test effects of torcetrapib on HDL and outcomes in high risk patients but was terminated early due to an unanticipated increase in mortality [16]. While the mechanism underlying this adverse effect of torcetrapib is unclear, it has been suggested that the CETP inhibitor may convert HDL from an anti-inflammatory particle to one that is dysfunctional and pro-atherogenic $[16,17]$. This raises the possibility that the function of HDL rather than its absolute serum level may be important.

As indicated by this discussion, multiple drug classes may exert beneficial effects on serum HDL concentration. Overall, the widespread use of these drugs as HDL-raising agents has been limited due to their modest stimulatory effect on the lipoprotein. It is also unclear whether these drugs improve the functional properties of HDL. The search for an ideal drug to raise HDL, therefore, goes on. The observation that HDL may become dysfunctional in some disease states is an evolving paradigm, and it has been suggested that the anti-inflammatory status of HDL may be of greater predictive value for CAD risk than HDL levels per se [18]. In this review, we discuss recent therapeutic approaches for raising HDL that involve the application of apoA-I itself. Specifically, we discuss anti-atherogenic and vasculoprotective effects of apoA-I mimetic peptides, molecules that improve the anti-inflammatory properties of HDL.

\section{OXIDATIVE MECHANISMS IN ATHEROSCLE- ROSIS}

Vascular function is compromised in a number of cardiovascular conditions including stroke, hypertension and atherosclerosis. In atherosclerosis, blood vessels undergo marked changes in both structure (cellular infiltration/proliferation, lipid deposition) and function (vasospasm, impaired vasodilation) that may predispose for angina and myocardial infarction. Defects in lipoprotein metabolism and vascular reactivity are fundamental pathological responses to hypercholesterolemia, with extensive evidence suggesting that reactive oxygen species play an important role in the initiation and progression of these pathological responses [19-21].

Nitric oxide (NO) becomes modified in a hyperlipidemic environment via its interaction with superoxide anion radical $\left(\mathrm{O}_{2}{ }^{-}{ }^{-}\right)$, resulting in diminished physiological activity [20, 21]. Superoxide is generated in both intracellular and extracellu- lar compartments in response to activation of the pro-oxidant enzymes, including NADPH oxidase, and reacts with the more membrane-permeable and diffusible NO, yielding the potent oxidant peroxynitrite $\left(\mathrm{ONOO}^{-}\right)$[22-24]. Clinically, excess production of $\mathrm{O}_{2}{ }^{-}$and $\mathrm{ONOO}^{-}$is associated with: 1) inhibition of endothelium-dependent vasodilatation; 2) enhanced formation of lipid peroxidation products; 3 ) increased expression of adhesion molecules and chemokines; 4) increased incorporation of proinflammatory cells (neutrophils, macrophages) by the vessel wall; 5) vascular cell proliferation, and, 6) thrombogenesis [25-27]. Pharmacological therapy that targets a reduction in oxidant formation while also stimulating NO formation may effectively blunt or even reverse these atherogenic processes.

The adhesion and infiltration of leukocytes in the vessel wall is a critical component of tissue injury in atherosclerosis and results in increased vascular permeability, elevated activities of oxidative enzymes, endothelial dysfunction and foam cell formation [28-33]. Myeloperoxidase (MPO) is a heme protein synthesized in granules of neutrophils found in atherosclerotic lesions that catalyzes the addition of chloride to hydrogen peroxide $\left(\mathrm{H}_{2} \mathrm{O}_{2}\right)$, resulting in the formation of the potent oxidant hypochlorous acid $(\mathrm{HOCl})[34,35]$. MPO has been identified as a CAD risk factor [36], and mechanistic links between the loss of bioavailable NO and MPO activity in the vasculature have been established [37]. MPO also catalyzes chlorination and nitration reactions in vascular cells [34, 38, 39]. Chlorinated and nitrated protein tyrosine residues have been detected in human atherosclerotic lesions, thus implicating MPO and $\mathrm{HOCl}$ as mediators of atherogenesis [38].

Myeloperoxidase has also been co-localized with macrophages in human atherosclerotic lesions [40, 41]. Recent evidence shows that MPO and $\mathrm{HOCl}$ modify both LDL and HDL under in vivo and in vitro conditions [42, 43]. The apoB moiety of LDL normally plays an important role in the receptor-mediated endocytosis of the lipoprotein. Oxidative modification of apoB, however, promotes foam cell formation and the development of fatty lesions. Data suggest that reaction products of MPO increase the nitration of apoB tyrosyl residues of LDL [44]. Exposure of macrophages to this nitrated-LDL promotes a greater accumulation of cholesterol and cholesteryl esters compared to treatment of cells with unmodified LDL [44]. The oxidative tyrosylation of HDL by MPO converts it to a form that is resistant to metabolism by hepatic enzyme systems and/or receptor-mediated uptake. In this manner, MPO contributes to atherogenesis by inhibiting the hepatic processing of HDL and, thus, reverse cholesterol transport [43]. The HOCl-mediated chlorination of apoA-I has also been shown to impair the ability of HDL to act as an acceptor for ATP-binding cassette transporter A1 (ABCA1)mediated cholesterol efflux from macrophages [45].

\section{ANTI-ATHEROGENIC PROPERTIES OF HDL}

LDL and very low-density lipoprotein (VLDL) are proinflammatory and pro-atherogenic particles, while HDL exerts opposing effects [46, 47]. HDL and apoA-I also possess anti-oxidant properties that prevent the oxidative modification of LDL [48, 49] and anti-inflammatory properties that include inhibition of endothelial cell adhesion molecule 
(VCAM, ICAM) expression [46]. ApoA-I comprises approximately $70 \%$ of total HDL protein and is thought to confer anti-atherogenic properties upon the lipoprotein particle. ApoA-I is synthesized and secreted from the liver as lipidpoor pre- $\beta$ HDL particles. Pre- $\beta$ HDL mediates a critical step in reverse cholesterol transport, a process by which cholesterol is removed from peripheral tissues and targeted to the liver for disposal. This is achieved via interaction of the particle with the ATP binding cassette transporter A-1 (ABCA-1) which mediates cholesterol efflux from target tissues. Lipid-poor HDL can subsequently be converted to a "mature" HDL particle via the action of lecithin-cholesterol acyltransferase (LCAT), an HDL-associated enzyme that converts the discoidal particle to a spherical particle containing cholesteryl ester in the core.

Anti-oxidant properties of HDL are attributed to apoA-I as well as the enzymes paraoxonase (PON) and platelet activating factor-acetyl hydrolase (PAF-AH) [50]. PON and PAF-AH hydrolyze oxidized phospholipids, thus reducing lipid peroxide content in LDL and VLDL [51, 52]. The critical importance of PON is underscored by findings that HDL particles isolated from mice that over express the gene for PON are highly resistant to lipid hydroperoxide formation induced by copper [52]. Conversely, a reduction in PON activity is associated with dyslipidemia in LDL receptordeficient mice and diabetic humans [53, 54]. By virtue of its capacity to act as a sink for oxidized lipids, HDL reduces the atherogenicity of apoB-containing lipoproteins [50]. In addition to reducing inflammatory responses induced by oxidized LDL (oxLDL), HDL may also reduce binding of circulating monocytes to the vascular endothelium via inhibition of adhesion molecule expression [46].

\section{PRO-INFLAMMATORY HDL}

HDL is commonly viewed as the "good cholesterol" largely due to its ability to mediate cholesterol efflux from peripheral tissues. The proposal that HDL may become dysfunctional in some disease states is an emerging concept in the field of CV biology [55]. Atherosclerosis is characterized by the development of a systemic inflammatory response that influences HDL function [56]. Activation of an acute phase response produces changes in HDL that are characterized by the loss of apoA-I and PON and incorporation of acute phase proteins [56]. Remodeling of the HDL particle is associated with a reduction in reverse cholesterol transport, an increase in lipoprotein oxidation and stimulation of oxLDL-mediated inflammatory responses [56-58]. In patients who have undergone cardiac surgery, an acute phase response is induced that is associated with an increased incorporation of ceruloplasmin in HDL compared to HDL isolated from pre-surgical samples. Under in vitro conditions, this acute phase HDL lost its ability to inhibit LDL-induced chemokine formation, monocyte chemotaxis and lipid hydroperoxide formation in cultured endothelial cells [57].

As noted previously, the MPO-derived oxidant hypochlorous acid degrades HDL function by oxidizing apoA-I [59]. This modification was associated with an impaired capacity of HDL to mediate reverse cholesterol transport [59]. Other in vitro studies show that elevated glucose decreases HDL-associated PON activity, suggesting a mechanism by which hyperglycemia reduces anti-oxidant capacity in the context of diabetes [60]. The composition of the HDL particle also influences its functional properties. An increase in HDL triglyceride content is associated with the loss of apoAI and an increase in the hepatic clearance of the lipoprotein [61]. Thus, hypertriglyceridemia may contribute to atherogenesis by lowering HDL levels and impairing reverse cholesterol transport. An increase in apoA-II expression relative to apoA-I is also associated with increased plasma VLDL and decreased HDL concentration [62]. Under these conditions, the anti-oxidant capacity of HDL is significantly reduced [62].

Additional support for the concept of "pro-inflammatory HDL" comes from the Framingham Study which showed that $40 \%$ of CAD events occurred in individuals with "normal" to "high" HDL levels. This observation suggested that functional properties of HDL, rather than absolute serum HDL concentration, may dictate its atheroprotective actions [63]. An HDL inflammatory index has recently been developed as a means to assess the functional quality of HDL [64]. This measurement is based on the ex vivo capacity of HDL to inhibit monocyte chemotactic activity in cultured endothelial cells [64]. Assessment of HDL isolated from atherosclerotic rabbits revealed an increase in the inflammatory index that positively correlated with circulating levels of the acute phase reactant serum amyloid A [64].

\section{RECONSTITUTED HDL AS A THERAPEUTIC TOOL}

HDL therapy, to date, has consisted of the use of molecules that are modified forms of apoA-I. In the presence of phospholipids, apoA-I forms discoidal HDL particles that incorporate cholesterol in the esterified form to yield mature, spherical HDL-like particles which possess cholesteryl ester in the core [65]. Clinical studies also show that infusion of apoA-I/phospholipid complexes in humans transiently increases HDL levels [66]. ApoA- $\mathrm{I}_{\text {Milano }}$ is a novel variant of apoA-I that was originally identified in carriers who were at low risk for development of CAD. ApoA-I $\mathrm{I}_{\text {Milano }}$ is characterized by the substitution of cysteine for arginine at position 173 in the native apoA-I molecule. The molecule exists in the monomeric, homodimeric and heterodimeric form with apo A-II. The presence of the thiol group in apoA- $\mathrm{I}_{\text {Milano }}$ is thought to confer enhanced antioxidant activity which may account for the potent anti-atherogenic properties of apoA$\mathrm{I}_{\text {Milano }}$ [67]. Laboratory studies show that apoA- $\mathrm{I}_{\text {Milano }}$ is more effective than wild type apoA-I in inhibiting lipoxygenaseinduced lipid oxidation [67]. This antioxidant activity was dependent on the association of apoA- $\mathrm{I}_{\text {Milano }}$ with phospholipid to form HDL-like particles. Subsequent studies, performed in $\operatorname{apoE}^{-/-}$mice, showed that apoA- $\mathrm{I}_{\text {Milano }}$ reduces the lipid and macrophage content of arteries and prevents the progression of atherosclerosis [68]. ApoA- $\mathrm{I}_{\text {Milano }}$ has recently undergone clinical evaluation. In a small clinical study, patients with established CAD were randomized to receive either intravenous recombinant apoA-I $\mathrm{I}_{\text {Milano }}(45 \mathrm{mg} / \mathrm{kg})$ and phospholipid $(45 \mathrm{mg} / \mathrm{kg})$ or placebo weekly for a 5 week treatment period [69]. Coronary atheroma burden was measured at baseline and after 5 weeks by intra-vascular ultrasound (IVUS). Study results showed that atheroma volume was reduced by $4.2 \%$ in patients receiving apoA- $\mathrm{I}_{\text {Milano }}$ [69]. While these results show promise for apoA- $\mathrm{I}_{\text {Milano }}$ as a thera- 
peutic agent, the study required intravenous administration of the drug and use of a relatively large amount of protein in the form of a protein-lipid complex [69]. The effect of phospholipid administration alone was not tested.

\section{STRUCTURAL CHARACTERISTICS OF APOA-I}

The amphipathic helix is a secondary structural motif found in many biologically active peptides and proteins. It is defined as an $\alpha$-helix with opposing polar and nonpolar faces oriented along its long axis. These regions are hydrophilic and hydrophobic in nature, respectively. This sidedness of the helix forms a structure complementary to that of phospholipids, thus facilitating their interaction with phospholipids to form protein:lipid complexes [70]. The amphipathic $\alpha-$ helix is a common motif found in exchangeable apolipoproteins, peptide hormones, antibacterial peptides and other biologically active peptides. It is categorized as 1 of 7 distinct classes: A, H, L, G, K, C and M [70]. Each class has a distinct charge, charge distribution and charge density. Class A amphipathic $\alpha$-helixes, a common structural motif present in exchangeable apolipoproteins, are zwitterionic, and the positively charged amino acid residues cluster at the polarnonpolar interface while the negatively charged residues are at the center of the polar face.

\section{ApoA-I MIMETIC PEPTIDE DESIGN}

In 1985, we designed a model peptide with the sequence, Asp-Trp-Leu-Lys-Ala-Phe-Tyr-Asp-Lys-Val-Ala-Glu-LysLeu-Lys-Glu-Ala-Phe, that, when folded into an $\alpha$-helix, possessed characteristics of a class A amphipathic helix. This peptide was designated 18A due to the presence of 18 amino acids and a class A structural motif. Addition of $18 \mathrm{~A}$ to a suspension of dimyristoyl phosphatidylcholine (DMPC) induced the formation of discoidal complexes that were structurally similar to those obtained by addition of apoA-I [71]. The ability of 18A-DMPC complexes to mediate cellular cholesterol efflux was assessed in cultured mouse fibroblasts and macrophages. This study showed that, when 18A was used as a cholesterol acceptor, the initial rate of cholesterol removal was similar to that of apoA-I [72]. In addition to forming small lipoprotein particles, 18A, like apoA-I, was able to activate the enzyme LCAT [73]. The model peptide $18 \mathrm{~A}$ was thus able to mimic many of the properties of apoAI. Refinements in peptide design showed that addition of an acetyl group at the amino terminus and an amide at the carboxyl terminus of $18 \mathrm{~A}$ (Ac-18A- $\mathrm{NH}_{2}$ ) increased the helicity of the peptide in solution and when associated with lipid [74]. By blocking $\mathrm{N}$ - and C-terminal ends of the peptide, the efficiency of Ac-18A- $\mathrm{NH}_{2}$ for associating with phospholipids was enhanced. This was associated with an increase in cholesterol efflux capability and LCAT activation compared to the unblocked peptide 18A [74].

Detailed studies of the physical-chemical characteristics of class A peptides revealed that the hydrophobic region of the peptide was critical in determining its biological activity. This lead to the development of a family of apoA-I mimetic peptides that are structural variants of the basic 18A motif. The lipid binding ability of $18 \mathrm{~A}$ is due to its hydrophobic face which contains 2 phenylalanine $(\mathrm{F})$ residues. By systematically replacing existing nonpolar amino acids on $18 \mathrm{~A}$ with $\mathrm{F}$ residues, we generated new peptides with increased hydrophobicity and lipid binding affinity $(3 \mathrm{~F}, 4 \mathrm{~F}, 5 \mathrm{~F}, 6 \mathrm{~F}$, $7 \mathrm{~F})$ [75]. There was a significant increase in the hydrophobicity between peptides $4 \mathrm{~F}$ and $5 \mathrm{~F}$ that was accompanied by increased ability to associate with phospholipids. Phospholipid binding with peptides $6 \mathrm{~F}$ and $7 \mathrm{~F}$ was reduced, suggesting a limit to increased hydrophobicity of these peptides to interact with lipid. Peptide $4 \mathrm{~F}$ was more effective than $5 \mathrm{~F}$ in inhibiting LDL-induced monocyte chemotactic activity, while the latter peptide showed the greatest capacity for LCAT activation [75]. It should be noted that while apo A-I does not solubilize 1-palmitoyl 2-oleoyl phosphatidylcholine (POPC) or egg phosphatidylcholine, the peptides $2 \mathrm{~F}, 4 \mathrm{~F}$ and $5 \mathrm{~F}$ are able to solubilize these lipids to form discoidal HDLlike structures. These HDL-like structures have high capacity to efflux cellular cholesterol and also possess antioxidant and antiinflammatory properties [75].

\section{ApoA-I MIMETIC PEPTIDES AND ATHEROGENIC LESION FORMATION IN MICE}

The first in vivo demonstration that apoA-I mimetic peptides possess anti-atherosclerotic properties utilized the hydrophobic peptide $5 \mathrm{~F}$ [76]. In this study, C57BL/6J mice were fed an atherogenic diet, and $5 \mathrm{~F}$ was administered daily by intraperitoneal injection for 16 weeks. At the end of the treatment period, aortic atherosclerotic lesion area was significantly reduced in animals receiving $5 \mathrm{~F}$ compared to hyperlipidemic controls receiving either saline or mouse apoAI [76]. Surprisingly, total plasma cholesterol levels and lipoprotein profiles were not significantly different between the treated and control groups. In additional studies, HDL was isolated from $5 \mathrm{~F}$-treated mice for ex vivo analyses. Functional properties of isolated HDL fractions were significantly different. Specifically, 5F treatment resulted in HDL that was more effective than HDL isolated from vehicle-treated controls in inhibiting LDL-associated lipid hydroperoxide formation and LDL-induced monocyte chemotaxis [76]. These results suggested that atheroprotective mechanisms of $5 \mathrm{~F}$ action are not due to changes in lipoprotein profiles per se, but, rather, are mediated by an improvement in HDL quality and function and/or direct anti-inflammatory effects of the peptide itself [76].

In subsequent studies, the apoA-I mimetic peptide 4F has been used extensively to study atherogenic mechanisms in vivo and in vitro. This is due to the fact that $4 \mathrm{~F}$ displays improved solubility properties and is more effective in reducing LDL-induced monocyte chemotactic activity than 5F [75]. Increased interest in $4 \mathrm{~F}$ also derives from the observation that synthesis of the peptide using D-amino acids results in a molecule (D-4F) that is orally active. Oral treatment of LDL receptor null $\left(\mathrm{LDLR}^{-/}\right)$mice with $\mathrm{D}-4 \mathrm{~F}$ showed that the peptide could be detected in the circulation, whereas $4 \mathrm{~F}$ peptide synthesized from L-amino acids was absent [77]. D-4F reduced lesion formation in $\mathrm{LDLR}^{-/-}$mice, but, similar to $5 \mathrm{~F}$, did not induce appreciable changes in total plasma or HDLcholesterol [77]. HDL isolated from D-4F-treated mice was more effective in inhibiting the ex vivo oxidation of LDL, demonstrating an improvement in functional properties of the lipoprotein. Other studies show that D-4F treatment in hyperlipidemic rabbits reduces arterial lesion formation. This response was associated with a reduction in the HDL in- 
flammatory index but not total cholesterol or HDL cholesterol [64]. These data provide further evidence that the quality and function of HDL is a better predictor of lesion formation than HDL concentration, in agreement with the proposal by Ansell et al. [63].

Subsequent studies showed that oral administration of D4F to apo E-deficient mice resulted in the appearance of small cholesterol-containing particles in the plasma within $20 \mathrm{~min}$ [78]. These particles were characterized as pre- $\beta$ HDL by non-denaturing gel electrophoresis and were found to be enriched in apoA-I and to have increased PON activity. $\mathrm{D}-4 \mathrm{~F}$ administration was also associated with a reduction in the lipid hydroperoxide content of apoB-containing lipoproteins [78]. These results suggested that D-4F is able to induce formation of pre- $\beta$ HDL, the smallest class of HDL particle with the greatest capacity for cholesteryl ester uptake from peripheral cells [78].

D-4F acts synergistically with statins to reduce arterial lesion formation. Oral administration of pravastatin and D$4 \mathrm{~F}$, at doses which independently have no effect on plaque reduction, produced a $79 \%$ decrease in lesion formation in apo $\mathrm{E}^{-/-}$mice that was characterized by a prominent reduction in macrophage content [79]. Combination therapy rendered HDL anti-inflammatory by virtue of an increase in apoA-I levels and PON activity. Co-administration of low dose D$4 \mathrm{~F}$ and pravastatin in older apoE $\mathrm{E}^{-/-}$mice also induced plaque regression [79]. This was the first study to report an overall increase in HDL cholesterol levels in response to $4 \mathrm{~F}$ administration. In similar studies, D-4F and pravastatin was also found to render HDL isolated from cynomolgus monkeys anti-inflammatory [79].

\section{ApoA-I MIMETIC PEPTIDES IMPROVE ENDOTHE- LIUM-DEPENDENT RELAXATION}

Endothelium-dependent relaxation is impaired by hypercholesterolemia in both humans and experimental animals. This is manifested primarily by a loss of NO bioavailability with resulting changes in functional and structural properties of blood vessels. An increase in LDL may contribute to the development of endothelial dysfunction by uncoupling endothelial NO synthase (eNOS) activity [80]. NO production normally requires the transfer of electrons from co-factors to the heme prosthetic group of the enzyme. Association of heat shock protein 90 (hsp90) with eNOS stabilizes the enzyme, facilitates electron ( $\mathrm{e}^{-}$) transfer and augments NO production [80]. The principal mechanism underlying LDL-induced eNOS uncoupling is due to inhibition of hsp90-eNOS complex formation. Under these conditions, $\mathrm{O}_{2}$ may act as an $\mathrm{e}^{-}$ acceptor resulting in the generation of superoxide anion $\left(\mathrm{O}_{2}{ }^{--}\right)$rather than $\mathrm{NO}[80]$.

Data suggest that $4 \mathrm{~F}$ modulates eNOS uncoupling in vitro and in vivo. Using bovine aortic endothelial cells (BAECs), Ou and colleagues showed that calcium ionophore-induced NO formation was reduced in cells that were pre-incubated with LDL [81]. This response was associated with an increase in $\mathrm{O}_{2}{ }^{-}$- formation. In contrast, pre-treatment of BAECs with LDL in the presence of $4 \mathrm{~F}$ reversed these effects. Enhanced formation of NO in 4F-treated BAECs was associated with an increased interaction between hsp90 and eNOS [81].
These studies have been extended under in vivo conditions by examining effects of 4F on endothelial dysfunction in LDL receptor-null ( $\mathrm{LDLR}^{-/}$) and sickle cell disease (SCD) mice [82]. Endothelial dysfunction in $\mathrm{LDLR}^{-/-}$mice is associated with LDL-induced eNOS uncoupling with concomitant $\mathrm{O}_{2}{ }^{\circ}$ generation. Chronic treatment with $4 \mathrm{~F}$ resulted in a significant improvement in the vasodilatory response of small arterioles from $\mathrm{LDLR}^{-/}$mice compared to animals receiving vehicle [82]. As in the cell culture studies, the improvement in endothelium-dependent relaxation was associated with a decrease in vascular $\mathrm{O}_{2}{ }^{-}$formation. In contrast to $\mathrm{LDLR}^{-/-}$mice, endothelial dysfunction in SCD mice is associated with an increase in the circulating concentration of the pro-oxidant enzyme xanthine oxidase (XO) [82]. Circulating $\mathrm{XO}$ binds to the vascular endothelium and, in the presence of xanthine substrate, reduces $\mathrm{NO}$ bioactivity by generating $\mathrm{O}_{2}{ }^{\circ-}$ [23]. Similar to $\mathrm{LDLR}^{-/-}$mice, $4 \mathrm{~F}$ treatment improved endothelial function in small arteries of SCD mice [82]. The authors proposed that the improved endothelial function in $\mathrm{LDLR}^{-/-}$mice was related to the ability of $4 \mathrm{~F}$ to reduce the atherogenicity and pro-inflammatory properties of LDL. In the case of SCD mice, it was suggested that 4F may reduce oxidative stress in the vessel wall and prevent the formation of inflammatory lipid mediators. A common mechanism, therefore, to explain vasoprotective effects of $4 \mathrm{~F}$ in these 2 distinct models may lie in the ability of the peptide to prevent the action and/or formation of inhibitory lipid metabolites [82].

Further evidence in support of a protective effect of $4 \mathrm{~F}$ on endothelium-dependent relaxation comes from studies in tight skin mice [83]. The tight skin mouse $\left(\mathrm{Tsk}^{-/+}\right)$is a commonly used model for systemic sclerosis (SSc), an autoimmune, connective tissue disorder in humans. Increased oxidant stress and endothelial dysfunction characterize the disorder in both humans and mice. Acetylcholine and flowinduced vasodilation were significantly impaired in arteries of $\mathrm{Tsk}^{-/+}$mice but were reversed by $4 \mathrm{~F}$ treatment [83]. Autoantibodies to oxidized phosphatidylcholine were also reduced by $4 \mathrm{~F}$ treatment suggesting that inflammatory lipid metabolites play a role in endothelial dysfunction in this model [83].

\section{ApoA-I MIMETIC PEPTIDES MODULATE ANTIO- XIDANT ENZYME EXPRESSION IN DIABETIC RATS}

Antioxidant effects of D-4F have been tested in streptozotocin (STZ)-treated, diabetic rats. Endothelial dysfunction in STZ rats is associated with vascular $\mathrm{O}_{2}{ }^{-}$formation and an increase in the number of circulating endothelial cells [84]. $4 \mathrm{~F}$ treatment improved vascular relaxation in STZ rats by reducing $\mathrm{O}_{2}{ }^{--}$formation and by preventing endothelial cell sloughing into the circulation. The improvement in endothelial integrity in 4F-treated STZ rats was due to an increase in the number of endothelial progenitor cells (EPCs) and expression of the endothelial cell marker $\mathrm{CD}^{+} 1^{+}$[84]. Protective effects of $4 \mathrm{~F}$ on vascular function and endothelial integrity were associated with an increase in the expression of the antioxidant enzymes heme oxygenase-1 (HO-1) and extracellular superoxide dismutase (EC-SOD) [84, 85]. Subsequent studies in type 2 diabetic $o b / o b$ mice showed that the 4F-mediated upregulation of HO-1 was associated with im- 
proved insulin sensitivity and glycemic control. 4F also increased serum adiponectin levels, reduced abdominal fat content and attenuated weight gain in $o b / o b$ mice. These exciting results suggest that, in addition to activating antioxidant enzyme expression, 4F treatment may activate metabolic pathways leading to an improvement in glucose disposal [86].

\section{ApoA-I MIMETICS ATTENUATE VASCULAR REM- ODELING IN TRANSPLANTATION MODELS}

Cardiac allograft vasculopathy (CAV) is a major cause of organ rejection and is characterized by vascular lymphocyte infiltration and intimal lesion formation. In recent studies, CAV was assessed in donor hearts transplanted in C57BL/6 mice that were treated with $4 \mathrm{~F}$ or saline [87]. $4 \mathrm{~F}$ treatment resulted in a significant reduction in intimal lesion size and a decrease in lymphocyte infiltration 24 days after transplantation. These protective effects were associated with induction of HO-1 in donor hearts and were partially blocked by an $\mathrm{HO}-1$ inhibitor [87]. In vitro studies also showed that $4 \mathrm{~F}$ reduced $\mathrm{T}$-lymphocyte proliferation and cytokine production by a mechanism that was HO- 1 independent. It was concluded that $4 \mathrm{~F}$ exerts dual protective effects. First, it reduces CAV by a mechanism that is HO-1-dependent. Second, it inhibits lymphocyte proliferation and cytokine formation in transplanted hearts by an alternate mechanism [87].

D-4F administration has also been shown to reduce atherosclerotic lesion formation in bypassed vein grafts. In these studies, a segment of inferior vena cava was grafted onto the right carotid artery of apoE-/- mice [88]. Lesion development in vein grafts was assessed 4 weeks later in mice that were treated with D-4F or saline vehicle. Native lesions in the aortic sinus served as a control. In 4F-treated animals, graft lesion size, plaque lipid content and macrophage immunoreactivity were reduced [88]. In contrast, native aortic lesions were not influenced by 4F treatment. These results suggested that $4 \mathrm{~F}$ treatment was effective in reducing evolving atherosclerotic lesions but had less effect in reducing those already established [88].

\section{NEW DIRECTIONS IN APOLIPOPROTEIN MIM- ETIC PEPTIDE DESIGN}

An emerging area in the field of HDL therapy is the development of peptides with apoE functional properties. ApoE is associated with VLDL and HDL. It contains a lipid associating domain and a globular domain containing the LDL receptor binding site [89]. The presence of the LDL receptor domain facilitates the hepatic clearance of cholesteryl esters, resulting in a significant decrease in plasma total cholesterol [90]. A peptide encoding an arginine-rich region (residues 141-150: LRKLRKRLLR) of the putative LDL receptor binding sequence, linked to $18 \mathrm{~A}$, has been synthesized $[89,91]$. The peptide was acetylated and amidated at the $\mathrm{C}$ - and $\mathrm{N}$-termini respectively to yield the stabilized peptide Ac-hE [141-150]18A-NH (Ac-hE18A-NH $_{2}$ ). AchE18A-NH $\mathrm{NH}_{2}$ associates with LDL and VLDL and targets these lipoproteins to hepatocytes for clearance via binding to heparan sulfate proteoglycans (HSPG) $[89,91]$. This effect is similar to increasing the addition of apo $E$ to the surface of VLDL which redirects VLDL to HSPG for enhanced uptake by hepatocytes. This peptide dramatically reduces plasma cholesterol in apo E-knockout mice [91]. Similar to apoA-I mimetic peptides, Ac-hE18A-NH $\mathrm{NH}_{2}$ is able to bind to phospholipids with high affinity but has the additional advantage of facilitating cholesterol clearance due to the presence of the LDL receptor binding domain. We previously reported that a single injection of Ac-hE18A- $\mathrm{NH}_{2}$ to hyperlipidemic Watanabe rabbits significantly reduces plasma cholesterol, an effect that was maintained for up to 3 days [92]. Fractionation of plasma samples after $24 \mathrm{~h}$ confirmed a significant lowering of VLDL and LDL. Ac-hE18A-NH 2 also reduced superoxide formation and improved endothelial function in isolated blood vessels of these animals [92].

Other HDL-modifying peptides that are currently under study include a class $\mathrm{G}^{*}$ amphipathic helix corresponding to amino acids at positions 113-122 of apoJ and small tetrapeptides (KRES and FREL) that do not form helices but interact with HDL [93]. The apoJ peptide exerts anti-atherogenic and anti-inflammatory effects by reducing lipoprotein-associated lipid hydroperoxides and by enhancing the activity of PON [94]. The 4 amino acid peptide KRES exerts similar effects on HDL quality but also increases HDL levels in apoE ${ }^{-/-}$ mice [94]. Despite these effects on HDL, KRES does not induce pre- $\beta$ HDL formation or directly stimulate cholesterol efflux from macrophages [94]. This is in contrast to the known effects of apoA-I mimetic peptides such as D-4F. Ongoing studies are defining mechanisms of small peptide action.

\section{CONCLUSIONS}

Apolipoprotein mimetic peptides are an evolving class of drugs with novel modulatory effects on plasma lipoproteins. Animal studies show that apoA-I peptide mimetics, such as $4 \mathrm{~F}$, do not directly alter plasma total cholesterol per se but improve HDL anti-atherogenic function by increasing the formation of HDL-like (pre- $\beta$ HDL) particles with elevated PON activity. These responses are linked to a reduction in the lipid hydroperoxide content in apo B-containing lipoproteins and stimulation of cholesterol efflux from foam cells. Indeed, recent studies show that the binding affinity of $4 \mathrm{~F}$ with oxidized products of 1-palmitoyl-2-arachidonoyl-snglycero-3-phosphatidylcholine is 4-6 orders of magnitude higher than that of apoA-I itself [95]. Vasoprotective effects of apolipoprotein mimetics also include an increase in the expression of HO-1 and EC-SOD. Antioxidant enzyme induction decreases oxidant stress and the formation of proinflammatory lipid peroxides, while improving NO bioavailability and endothelial cell function. Whether the induction of HO-1 and EC-SOD is a direct effect of $4 \mathrm{~F}$ or is related to improvement in HDL function is currently unknown.

A preliminary evaluation of $\mathrm{D}-4 \mathrm{~F}$ in high-risk CAD patients has recently been completed. Subjects were randomized to receive a single dose $(30-500 \mathrm{mg})$ of D-4F orally or placebo [66]. Results show that unformulated D-4F has a low bioavailability but is safe and well-tolerated. Perhaps, the most important finding of this study was the observation that D-4F treatment reduced the HDL inflammatory index in high risk subjects [96]. The next step in the clinical evaluation of $4 \mathrm{~F}$ will be to test whether multiple oral doses of D-4F improve HDL function in CAD patients. 


\section{REFERENCES}

[1] Gordon T, Kannel WB, Castelli WP, et al. Lipoproteins, cardiovascular disease, and death. The Framingham study. Arch Intern Med 1981; 141: 1128-31.

[2] Brousseau ME. Emerging role of high-density lipoprotein in the prevention of cardiovascular disease. Drug Discov Today 2005; 10: 1095-101.

[3] Wiviott SD, Cannon CP. Update on lipid-lowering therapy and LDL-cholesterol targets. Nat Clin Prac Cardiovasc Med 2006; 3: 424-36.

[4] Castelli WP. Cholesterol and lipids in the risk of coronary heart disease: the Framingham Heart Study. Can J Cardiol 1988; 4: 5A$10 \mathrm{~A}$.

[5] Linsel-Nitschke P, Tall AR. HDL as a target in the treatment of atherosclerotic cardiovascular disease. Nat Rev Drug Discov 2005; 4: 193-205.

[6] Belalcazar LM, Ballantyne CM. Defining specific goals of therapy in treating dyslipidemia in the patient with low high-density lipoprotein cholesterol. Prog Cardiovasc Dis 1998; 41: 151-74.

[7] Gnasso A, Lehner B, Haberbosch W, et al. Effect of gemfibrozil on lipids, apoproteins, and postheparin lipolytic activities in normolipidemic subjects. Metabolism 1985; 35: 387-93.

[8] Wierzbicki AS, Mikhailidis DP, Wray R, et al. Statin-fibrate combination: therapy for hyperlipidemia: a review. Curr Med Res Opin 2003; 19: 155-168.

[9] Malik S, Kashyap ML. Niacin, lipids, and heart disease. Curr Cardiol Rep 2003; 5: 470-476.

[10] Maron DJ, Fazio S, Linton MF. Current perspectives on statins. Circulation 2000; 101: 207-213.

[11] Chapman MJ. Are the effects of statins on HDL-cholesterol clinically relevant? Eur Heart J 2004; 6: C58-C63.

[12] Schaefer JR, Schweer H, Ikewaki K, et al. Metabolic basis of high density lipoproteins and apolipoprotein A-I increase by HMG-CoA reductase inhibition in healthy subjects and a patient with coronary artery disease. Atherosclerosis 1999; 144: 177-184.

[13] Barter PJ, Brewer HB, Chapman MJ, et al. Cholesteryl ester transfer protein: a novel target for raising HDL and inhibiting atherosclerosis. Arterioscler Thromb Vasc Biol 2003; 23: 160-167.

[14] Morehouse LA, Sugarman ED, Bourassa P-A, et al. Inhibition of CETP activity by torcetrapib reduces susceptibility to diet-induced atherosclerosis in NZW rabbits. J Lipid Res 2007; 48: 1263-1272.

[15] Brousseau ME, Schaefer EJ, Wolfe ML, et al. Effects of an inhibitor of cholesteryl ester transfer protein on HDL cholesterol. N Engl J Med 2004; 350: 1505-1515.

[16] Barter PJ, Caulfield M, Eriksson M, et al. Effects of torcetrapib in patients at high risk for coronary events. N Engl J Med 2007; 357: 2109-2122.

[17] Kontush A, Guerin M, Chapman MJ. Spotlight on HDL-raising therapies: insights from the torcetrapib trials. Nat Clin Pract 2008; 5: 329-336.

[18] deGoma EM, deGoma RL, Rader DJ. Beyond high-density lipoprotein cholesterol levels. Evaluating high-density lipoprotein function as influenced by novel therapeutic approaches. J Am Coll Cardiol 2008; 51: 2199-2211.

[19] White CR, Brock TA, Chang LY, et al. Superoxide and peroxynitrite in atherosclerosis. Proc Natl Acad Sci USA 1994; 91: 10441048.

[20] Darley-Usmar V, White R. Disruption of vascular signaling by the reaction of nitric oxide with superoxide: implications for cardiovascular disease. Exp Physiol 1997; 82: 305-316.

[21] Darley-Usmar VM, McAndrew J, Patel R, et al. Nitric oxide, free radicals and cell signaling in cardiovascular disease. Biochem Soc Transactions 1997; 25: 925-930.

[22] Griendling KK, Sorescu D, Ushio-Fukai M. NAD(P)H oxidase: role in cardiovascular biology and disease. Circulation Res 2000; 86: 494-501.

[23] White CR, Darley-Usmar V, McAdams M, et al. Circulating plasma xanthine oxidase contributes to vascular dysfunction in hypercholesterolemic rabbits. Proc Natl Acad Sci USA 1996; 93: 8745-8749.

[24] Zhang C, Kelpke S, Ma W, et al. Endothelial dysfunction is induced by the proinflammatory oxidant hypochlorous acid. Am J Physiol 2001; 281: H1469-H1475.
[25] Spiecker M, Darius H, Kaboth K, et al. Differential regulation of endothelial cell adhesion molecule expression by nitric oxide donors and antioxidants. J Leukoc Biol 1998; 63: 732.

[26] Haller H. Endothelial function: general consideration. Drugs 1997; 53: 1

[27] Muenzel T, Heitzer T, Harrison DG. The physiology and pathophysiology of the nitric oxide/superoxide system. Herz 1997; 22: 158.

[28] Heinecke JW. Mechanisms of oxidative damage by myeloperoxidase in atherosclerosis and other inflammatory disorders. J Lab Clin Med 1999; 133: 321-325.

[29] Conner EM, Grisham MB. Inflammation, free radicals, and antioxidants. Nutrition 1996; 12: 274-277.

[30] Grisham MB, Granger DN, Lefer DJ. Modulation of leukocyteendothelial interactions by reactive metabolites of oxygen and nitrogen: relevance to ischemic heart disease. Free Radic Biol Med 1998; 25: 404-433.

[31] Vinten-Johansen J, Zhao ZQ, Nakamura M, et al. Nitric oxide and the vascular endothelium in myocardial ischemia-reperfusion injury. Ann N Y Acad Sci 1999; 874: 354-370.

[32] Wang P, Ba ZF, Cioffi WG, et al. Salutary effects of ATP- $\mathrm{MgCl}_{2}$ on the depressed endothelium-dependent relaxation during hyperdynamic sepsis. Crit Care Med 1999; 27: 959-964.

[33] Cameron EM, Wang SY, Fink MP, et al. Mesenteric and skeletal muscle microvascular responsiveness in subacute sepsis. Shock 1998; 9: 184-192.

[34] Eiserich JP, Hristova M, Cross CE, et al. Formation of nitric oxidederived inflammatory oxidants by myeloperoxidase in neutrophils. Nature 1998; 391: 393-397.

[35] Marcinkiewicz J. Nitric oxide and antimicrobial activity of reactive oxygen intermediates. Immunopharmacology 1997; 37: 35-41.

[36] Zhang R, Brennan ML, Fu X, et al. Association between myeloperoxidase levels and risk of coronary artery disease. JAMA 2001; 286: 2136-2142.

[37] Eiserich JP, Baldus S, Brennan ML, et al. Myeloperoxidase: a leukocyte-derived vascular NO oxidase. Science 2002; 296: 23912394.

[38] Hazen SL, Crowley JR, Mueller DM, et al. Mass spectrometric quantification of 3-chlorotyrosine in human tissues with attomole sensitivity: a sensitive and specific marker for myeloperoxidasecatalyzed chlorination at sites of inflammation. Free Radic Biol Med 1997; 23: 909-916.

[39] Eiserich JP, Cross CE, Jones AD, et al. Formation of nitrating and chlorinating species by reaction of nitrite with hypochlorous acid. A novel mechanism for nitric oxide-mediated protein modification. J Biol Chem 1996; 271: 19199-19208.

[40] Heinecke JW. Mechanisms of oxidative damage of low density lipoprotein in human atherosclerosis. Curr Opin Lipidol 1997; 8: 268-274.

[41] Heinecke JW. Pathways for oxidation of low density lipoprotein by myeloperoxidase: tyrosyl radical, reactive aldehydes, hypochlorous acid and molecular chlorine. Biofactors 1997; 6: 145-155.

[42] Yang CY, Gu ZW, Yang M, et al. Selective modification of apoB100 in the oxidation of low density lipoproteins by myeloperoxidase in vitro. J Lipid Res 1999; 40: 686-698.

[43] Guertin F, Brunet S, Lairon D, Levy E. Oxidative tyrosylation of high density lipoprotein impairs biliary sterol secretion in rats. Atherosclerosis 1997; 131: 35-41.

[44] Podrez EA, Schmitt D, Hoff HF, et al. Myeloperoxidase-generated reactive nitrogen species convert LDL into an atherogenic form in vitro. J Clin Invest 1999; 103: 1547-1560.

[45] Bergt C, Pennathur S, Fu X, et al. The myeloperoxidase product hypochlorous acid oxidizes HDL in the human artery wall and impairs ABCA1-dependent cholesterol transport. Proc Natl Acad Sci USA 2004; 101: 13032-13037.

[46] Ashby DT, Rye KA, Clay MA, et al. Factors influencing the ability of HDL to inhibit expression of vascular cell adhesion molecule-1 in endothelial cells. Arterioscler Thromb Vasc Biol 1998; 18: 14501455

[47] Cockerill GW, Huehns TY, Weerasinghe A, et al. Elevation of plasma high-density lipoprotein concentration reduces interleukin-1 induced expression of E-selectin in an in vivo model of acute inflammation. Circulation 2001; 103: 108-112.

[48] Navab M, Hama SY, Cooke CJ, et al. Normal high density lipoprotein inhibits three steps in the formation of mildly oxidized low density lipoprotein: step 1. J Lipid Res 2000; 41: 1481-1494. 
[49] Navab M, Hama SY, Anantharamaiah GM, et al. Normal high density lipoprotein inhibits three steps in the formation of mildly oxidized low density lipoprotein: step 2 and 3. J Lipid Res 2000; 41: 1495-1508.

[50] Barter PJ, Nicholls S, Rye KA, et al. Antiinflammatory properties of HDL. Circ Res 2004; 95: 764-772.

[51] Mackness B, Durrington PN, Boulton AJ, et al. Serum paraoxonase activity in patients with type 1 diabetes compared to healthy controls. Eur J Clin Invest 2002; 32: 259-264.

[52] Oda MN, Bielicki JK, Ho TT, et al. Paraoxonase 1 over expression in mice and its effect on high-density lipoproteins. Biochem Biophys Res Commun 2002; 290: 921-927.

[53] Mertens A, Verhamme P, Bielicki JK, et al. Increased low-density lipoprotein oxidation and impaired high-density lipoprotein antioxidant defense are associated with increased macrophage homing and atherosclerosis in dyslipidemic obese mice: LCAT gene transfer decreases atherosclerosis. Circulation 2003; 107: 1640-1646.

[54] Sanguinetti SM, Brites FD, Fasulo V, et al. HDL oxidability and its protective effect against LDL oxidation in type 2 diabetic patients. Diabetes Nutr Metab Clin Exp 2001; 14: 27-36.

[55] Navab M, Anantharamaiah GM, Reddy ST, et al. Mechanisms of disease: proatherogenic HDL-an evolving field. Nat Clin Pract 2006; 2: 504-511.

[56] Navab M, Anantharamaiah GM, Fogelman AM. The role of highdensity lipoprotein in inflammation. Trends Cardiovasc Med 2005; 15: $158-161$

[57] Van Lenten BJ, Hama SY, de Beer FC, et al. Anti-inflammatory HDL becomes pro-inflammatory during the acute phase response. $\mathrm{J}$ Clin Invest 1995; 96: 2758-2767.

[58] Fogelman AM. When good cholesterol goes bad. Nat Med 2004; 10: $902-903$.

[59] Bergt C, Pennathur S, Fu X, et al. The myeloperoxidase product hypochlorous acid oxidizes HDL in the human artery wall and impairs ABCA1-dependent cholesterol transport. Proc Natl Acad Sci USA 2004; 101: 13032-13037.

[60] Ferretti G, Bacchetti T, Marchionni C, et al. Effect of glycation of high density lipoproteins on their physicochemical properties and on paraoxonase activity. Acta Diabetol 2001; 38: 163-169.

[61] Lamarche B, Uffelman KD, Carpentier A, et al. Triglyceride enrichment of HDL enhances in vivo metabolic clearance of HDL apo A-I in healthy men. J Clin Invest 1999; 103: 1191-1199.

[62] Boisfer E, Stengel D, Pastier D, et al. Antioxidant properties of HDL in transgenic mice overexpressing human apolipoprotein A-II. J Lipid Res 2002; 43: 732-741.

[63] Ansell BJ, Navab M, Hama S, et al. Inflammatory/antiinflammatory properties of high density lipoprotein distinguish patients from control subjects better than high density lipoprotein cholesterol levels and are favorably affected by simvastatin treatment. Circulation 2003; 108: 2751-2756

[64] Van Lenten BJ, Wagner AC, Navab M, et al. Lipoprotein inflammatory properties and serum amyloid A levels but not cholesterol levels predict lesion area in cholesterol-fed rabbits. J Lipid Res 2007; 48: 2344-2353.

[65] Hirz R, Scanu AM. Reassembly in vitro of a serum high density lipoprotein. Biochim Biophys Acta 1970; 207: 364-370.

[66] Eriksson M, Carlson LA, Miettinen TA, et al. Stimulation of fecal steroid excretion after infusion of recombinant proapolipoprotein A-I. Potential reverse cholesterol transport in humans. Circulation 1999; 100: 594-598.

[67] Bielicki JK, Oda MN. Apolipoprotein A- $\mathrm{I}_{\text {Milano }}$ and apolipoprotein

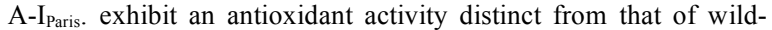
type apolipoprotein A-I. Biochemistry 2002; 41: 2089 -2096.

[68] Shah PK, Yano J, Reyes O, et al. High-dose recombinant apolipoprotein A-Imilano mobilizes tissue cholesterol and rapidly reduces plaque lipid and macrophage content in apolipoprotein E-deficient mice: potential implications for acute plaque stabilization. Circulation 2001; 103: 3047-3050.

[69] Nissen SE, Tsunoda T, Tuzcu EM, et al. Effect of recombinant apoA-I milano on coronary atherosclerosis in patients with acute coronary syndromes: a randomized controlled trial. JAMA 2003; 290: 2292-2300

[70] Segrest JP, Garber DW, Brouillette CG, et al. The amphipathic $\alpha$ helix: A multifunctional structural motif in plasma apolipoproteins. Adv Prot Chem 1994; 45: 303-369.

[71] Anantharamaiah GM, Jones JL, Brouillette CG, et al. Studies of synthetic peptide analogs of the amphipathic helix. Structure of complexes with dimyristoyl phosphatidylcholine. J Biol Chem 1985; 260: 10248-10255.

[72] Mendez AJ, Anantharamaiah GM, Segrest JP, et al. Synthetic amphipathic helical peptides that mimic apolipoprotein A-I in clearing cellular cholesterol. J Clin Invest 1994; 94: 1698-1705.

[73] Epand RM, Gawish A, Iqbal M, et al. Studies of synthetic peptide analogs of the amphipathic helix. Effect of charge distribution, hydrophobicity, and secondary structure on lipid association and lecithin:cholesterol acyltransferase activation. J Biol Chem 1987; 262: 9389-9396.

[74] Venkatachalapathi YV, Phillips MC, Epand RM, et al. Effect of end group blockage on the properties of a class A amphipathic helical peptide. Proteins 1993; 15: 349-359.

[75] Datta G, Chaddha M, Hama S, et al. Effects of increasing hydrophobicity on the physical-chemical and biological properties of a class A amphipathic helical peptide. J Lipid Res 2001; 42: 10961104

[76] Garber DW, Datta G, Chaddha M, et al. A new synthetic class A amphipathic peptide analogue protects mice from diet-induced atherosclerosis. J Lipid Res 2001; 42: 545-552.

[77] Navab M, Anantharamaiah GM, Hama S, et al. Oral administration of an Apo A-I mimetic peptide synthesized from D-amino acids dramatically reduces atherosclerosis in mice independent of plasma cholesterol. Circulation 2002; 105: 290-292.

[78] Navab M, Anantharamaiah GM, Reddy ST, et al. Oral D-4F causes formation of pre-beta high-density lipoprotein and improves highdensity lipoprotein-mediated cholesterol efflux and reverse cholesterol transport from macrophages in apolipoprotein E-null mice. Circulation 2004; 109: 3215-3220.

[79] Navab M, Anantharamaiah GM, Hama S, et al. D-4F and statins synergize to render HDL anti-inflammatory in mice and monkeys and cause lesion regression in old apolipoprotein E-null mice. Arterioscler Thromb Vasc Biol 2005; 25: 1426-1432.

[80] Stepp DW, Ou J, Ackerman AW, et al. Native LDL and minimally oxidized LDL differentially regulate superoxide anion in vascular endothelium in situ. Am J Physiol. 2002; 283: H750-H759.

[81] Ou Z, Ou J, Ackerman AW, et al. L-4F, an apolipoprotein A-1 mimetic, restores nitric oxide and superoxide anion balance in lowdensity lipoprotein-treated endothelial cells. Circulation. 2003; 107: 1520-1524

[82] Ou J, Ou Z, Jones DW, et al. L-4F, an apolipoprotein A-1 mimetic, dramatically improves vasodilation in hypercholesterolemia and sickle cell disease. Circulation 2003; 107: 2337-2341.

[83] Weihrauch D, Xu H, Shi Y, et al. Effects of D-4F on vasodilation, oxidative stress, angiostatin, myocardial inflammation, and angiogenic potential in tight-skin mice. Am J Physiol 2007; 293: H14321441.

[84] Peterson SJ, Husney D, Kruger AL, et al. Long-term treatment with the apolipoprotein A1 mimetic peptide increases antioxidants and vascular repair in type I diabetic rats. J Pharmacol Exp Ther 2007; 322: 514-520.

[85] Kruger AL, Peterson S, Turkseven S, et al. D-4F induces heme oxygenase-1 and extracellular superoxide dismutase, decreases endothelial cell sloughing, and improves vascular reactivity in rat model of diabetes. Circulation 2005; 111:3126-3134

[86] Peterson SJ, Drummond G, Hyun Kim D, et al. L-4F treatment reduces adiposity, increases adiponectin levels and improves insulin sensitivity in obese mice. J Lipid Res 2008; 49: 1658-1669.

[87] Hsieh GR, Schnickel GT, Garcia C, et al. Inflammation/oxidation in chronic rejection: apolipoprotein A-I mimetic peptide reduces chronic rejection of transplanted hearts. Transplantation 2007; 84: 238-243.

[88] Li X, Chyu KY, Faria Neto JR, et al. Differential effects of apolipoprotein A-I-mimetic peptide on evolving and established atherosclerosis in apolipoprotein E-null mice. Circulation 2004; 110: 1701-1705.

[89] Datta G, Chaddha M, Garber DW, et al. The receptor binding domain of apolipoprotein E, linked to a model class A amphipathic helix, enhances internalization and degradation of LDL by fibroblasts. Biochemistry 2000; 39: 213-220.

[90] Segall ML, Dhanasekaran P, Baldwin F, et al. Influence of apoE domain structure and polymorphism on the kinetics of phospholipid vesicle solubilization. J Lipid Res 2002; 43: 1688-1700.

[91] Datta G, Garber DW, Chung BH, et al. Cationic domain 141-150 of apoE covalently linked to a class A amphipathic helix enhances 
atherogenic lipoprotein metabolism in vitro and in vivo. J Lipid Res 2001; 42: 959-966.

[92] Gupta H, White CR, Handattu S, et al. An apolipoprotein E mimetic peptide dramatically lowers atherogenic lipoproteins and restores endothelial function in Watanabe heritable hyperlipidemic rabbits. Circulation 2005; 111:3112-3118.

[93] Reddy ST, Anantharamaiah GM, Navab M, et al. Oral amphipathic peptides as therapeutic agents. Expert Opin Investig Drugs 2006; 15: 13-21.

[94] Navab M, Anantharamaiah GM, Reddy ST, et al. An oral apoJ peptide renders HDL antiinflammatory in mice and monkeys and dramatically reduces atherosclerosis in apolipoprotein E-null mice. Arterioscler Thromb Vasc Biol 2005; 25: 1932-1937.

[95] Van Lenten BJ, Wagner AC, Jung CL, et al. Anti-inflammatory apoA-I mimetic peptides bind oxidized lipids with much higher af finity than human apoA-I. J Lipid Res 2008; 49: 2302-11.

[96] Bloedon L, Dunbar R, Duffy D, et al. Safety, pharmacokinetics and pharmacodynamics of a single dose of oral apolipoprotein A-I mimetic peptide D-4F in high-risk cardiovascular patients. J Lipid Res 2008; 49: 1344-1352.

(C) White et al.; Licensee Bentham Open.

This is an open access article licensed under the terms of the Creative Commons Attribution Non-Commercial License (http://creativecommons.org/licenses/by$\mathrm{nc} / 3.0 /$ ) which permits unrestricted, non-commercial use, distribution and reproduction in any medium, provided the work is properly cited. 